\title{
Hubungan Maternal Early Obstetric Warning Score (MEOWS) dengan Perawatan di Intensive Care Unit pada Pasien Preeklamsia Berat di RSUP Dr. Sardjito
}

\author{
Yosi Tamara ${ }^{1}$, Muhammad Lutfi ${ }^{2}$, Shinta Prawitasari ${ }^{3}$ \\ 1,2,3 Departemen Obstetri dan Ginekologi FK-KMK UGM \\ Korespondensi: jossie.tamara@gmail.com
}

Submisi: 5 September 2019; Revisi: 30 September 2019; Penerimaan: 21 November 2019

\begin{abstract}
ABSTRAK
Latar Belakang: Preeklamsia merupakan masalah kedokteran yang serius dan memiliki kompleksitas yang tinggi. Preeklamsia dapat setiap saat mengalami perburukan, sehingga dibutuhkan suatu metode yang mudah digunakan untuk mendeteksi dan mengidentifikasi adanya perburukan. Salah satunya adalah Modified Early Obstetrics Warning Score (MEOWS) yang merupakan salah satu parameter untuk memudahkan mendeteksi secara dini adanya risiko tinggi pada pasien obstetri. Diharapkan perburukan yang terjadi dapat dicegah atau dikurangi risikonya dengan menempatkan pasien preeklamsia berat menurut level of care disesuaikan dengan kebutuhan pasien.

Tujuan: Penelitian ini bertujuan untuk mencari cut off point skor MEOWS pada pasien preeklamsia berat dalam menentukan tempat perawatan.

Metode: Penelitian dengan desain kohort retrospektif. Data diambil dari rekam medis, dengan subyek penelitian yang memenuhi kriteria inklusi dan eksklusi. Data penelitian dikumpulkan, diolah dan dilakukan analisis data univariat, bivariat dan multivariat untuk mengetahui hubungan antar variabel.

Hasil dan Pembahasan: Sampel pada penelitian ini berjumlah 187 subyek penelitian. Karakteristik skor MEOWS IGD $\geq 8$ berjumlah 70 subyek dan skor MEOWS IGD $<8$ berjumlah 117 subyek. Pasien yang dirawat di ICU berjumlah 15 subyek dan yang dirawat selain di ICU berjumlah 174 subyek. Hasil perhitungan mendapatkan nilai cut off point skor MEOWS adalah 7,5 (dibulatkan menjadi skor 8). Terdapat hubungan bermakna antara skor MEOWS $\geq 8$ dengan perawatan di ICU (RR 3,34; Cl 95\%: 1,19-9,38). Terdapat hubungan yang bermakna juga antara skor MEOWS $\geq 8$ dengan kejadian bayi IUFD (RR 9,91; Cl 95\%: 2,098-40,27).

Kesimpulan: Pasien preeklamsia berat dengan skor MEOWS $\geq 8$ memiliki risiko untuk dirawat di ICU 3,34 kali lipat dibandingkan dengan pasien preeklamsia berat dengan skor MEOWS $<8$. Pasien preeklamsia berat dengan skor MEOWS $\geq 8$ memiliki risiko untuk kejadian bayi IUFD 9,91 kali lipat dibandingkan dengan pasien preeklamsia berat dengan skor MEOWS $<8$.
\end{abstract}

Kata Kunci: Modified Early Obstetric Warning Score (MEOWS); preeklamsia berat; intensive care unit

\begin{abstract}
Background: Preeclampsia is a serious medical problem and have high complexity. Because preeclampsia can experience deterioration at any time, it requires an easy method to use to detect and identify deterioration. One of them is Modified Obstetric Warning Score (MEOWS), which is one parameter to facilitate early detection of high risks in obstetric patients. It is expected that deterioration that occurs can be prevented or reduced the risk by placing patients with severe preeclampsia according to level of care of patients needed.

Objective: This study aims to find cut off point MEOWS score in severe preeclampsia patients in determining the level of care.

Method: Research with a retrospective cohort design. Data was collected is from medical records, with inclusion and exclusion criteria. Data was processed and analyzed using SPSS 22. Univariate, bivariate and multivariate data analysis was performed to determine the relationship between variables.

Results and Discussion: This study involved 187 subject, with characteristics of MEOWS IGD scores $\geq 8$ had 70 subjects and MEOWS $<8$ scores had 117 subjects. The patient were treated in intensive care unit 15 subjects and those treated in non-intensive care were 174 subjects. Obtained the cut off point MEOWS score is 7.5 (rounded off to score 8). There was a significant relationship between MEOWS scores $\geq 8$ with ICU care (RR 3.34; $95 \% \mathrm{Cl}$ : 1.19-9.38). There was a significant relationship also between MEOWS scores $\geq 8$ and the incidence of IUFD (RR 9.91; 95\% Cl: 2.098-40.27).

Conclusion: Severe preeclampsia with an MEOWS score $\geq 8$ had a risk of being admitted to the ICU 3.34 times compared with severe preeclampsia patients with MEOWS scores $<8$. Severe preeclampsia with an MEOWS score $\geq 8$ had a risk for the incidence IUFD of 9.91 times compared with severe preeclampsia patients with MEOWS scores $<8$.
\end{abstract}

Keywords: Modified Early Obstetric Warning Score (MEOWS); severe preeclampsia; intensive care unit 


\section{PENDAHULUAN}

Kematian dan kesakitan pada ibu hamil dan bersalin serta bayi baru lahir sejak lama telah menjadi masalah, khususnya di negara-negara berkembang. ${ }^{1}$ Angka kematian ibu di Indonesia pada tahun 2012 adalah 359 per 100.000 kelahiran hidup yang menunjukkan peningkatan dibandingkan dengan hasil angka kematian ibu untuk periode 5 tahun sebelumnya (2003-2007) yaitu 228 per 100.000 kelahiran hidup. ${ }^{2}$ Penelitian sebelumnya mendapatkan bahwa morbiditas maternal terbanyak adalah perdarahan (43\%), diikuti oleh penyakit hipertensi dalam kehamilan (31\%) dan infeksi (20\%). ${ }^{3}$

Preeklamsia merupakan masalah kedokteran yang serius dan memiliki tingkat kompleksitas yang tinggi, karena dapat secara cepat mengalami perburukan. ${ }^{4}$ Komplikasi yang terjadi dapat berupa komplikasi maternal (eklamsia, HELLP Syndrome, ruptur hati, edema paru, gagal ginjal, disseminated intravascular coagulopathy, hipertensi emergensi, encephalopathy hipertensi dan cortical blindness) maupun komplikasi fetal (pertumbuhan janin terhambat, oligohidramnion, placental abruption, kelahiran prematur, kematian bayi).5,6 Prevalensi preeklamsia dinegara maju adalah $1,3 \%$, sedangkan dinegara berkembang adalah 1,8-18\%.

Preeklamsia berat setiap saat dapat mengalami perburukan, sehingga dibutuhkan suatu metode yang mudah digunakan untuk mendeteksi dan mengidentifikasi secara relevan tanda dan gejala klinik yang muncul. ${ }^{4}$ Metode yang telah dikenal sejak tahun 1999 adalah Early Warning Score, early warning system dan rapid response system. ${ }^{7}$

Early Warning System yang telah digunakan saat itu dinilai sulit diterapkan pada pasien obstetri, karena pasien obstetri mengalami perubahan fisiologis pada fase kehamilan dan nifas. $^{7}$ Pada tahun 2013, Intensive Care National Audit and Research Centre Case Mix Programme Database mengembangkan Early Warning Score menjadi Modified Early Obstetrics Warning Score (MEOWS) sebagai salah satu metode untuk memudahkan mendeteksi secara dini adanya risiko tinggi pada pasien obstetri dengan dengan mempertimbangkan skoring statistik dan keputusan klinis. ${ }^{7,8}$
Pasien preeklamsia berat yang dirawat di fasilitas kesehatan dengan level tertentu harus dilakukan asessment untuk menilai kebutuhan perawatan pasien disesuaikan dengan diagnosis, pemeriksaan penunjang, terapi dan tindakan yang akan dilakukan. Saat ini belum ada penelitihan mengenai hubungan skor MEOWS dengan level of care pasien preeklamsia berta yang dirawat. Keadaan ini menyebabkan terjadinya perbedaan level of care dari masing-masing rumah sakit tergantung pada fasilitas dan sumberdaya manusia yang ada.

\section{METODE}

Penelitian ini merupakan studi dengan desain kohort retrospektif untuk menentukan cut off point skor MEOWS pasien preeklamsia berat yang dirawat di Intensive Care Unit, serta mencari hubungan antara skor MEOWS dengan tempat perawatan di Intensive Care Unit. Data subyek penelitian diambil dari rekam medis pasien yang dirawat di RSUP Dr. Sardjito pada tahun 2017 serta memenuhi kriteria inklusi dan eksklusi. Kriteria inklusi adalah pasien hamil yang terdiagnosis preeklamsia berat dan superimposed preeklamsia, serta menjalani rawat inap di RSUP Dr. Sardjito. Kriteria eksklusi adalah pasien dengan riwayat penyakit jantung sebelumnya, rwiayat penyakit paru-paru sebelumnya, riwayat gangguan hati sebelumnya dan riwayat penyakit ginjal sebelumnya.

\section{HASIL DAN PEMBAHASAN}

Subjek penelitian ini sebanyak 187 sampel. Tabel 1 menunjukkan sebagian besar subyek berada pada usia 20-35 tahun sebanyak 111 orang (59,4\%), dimana rata-rata usia subyek penelitian adalah 33,45 tahun dengan usia termuda 18 tahun dan usia tertua 47 tahun. Paritas sebagian besar subyek penelitian adalah multigravida sebanyak 127 orang $(67,9 \%)$ dibandingkan primigravida sebanyak 60 orang (32,1\%). Indeks massa tubuh (IMT) sebagian besar subyek penelitian adalah obesitas sebanyak 97 orang (51,9\%). Tingkat pendidikan sebagian besar subyek penelitian adalah SMA s/d Perguruan Tinggi sebanyak 119 orang $(63,6 \%)$. Sebagian besar subyek penelitian memiliki asuransi kesehatan baik BPJS, Jamkesos maupun asuransi lainnya. Subyek 
penelitian yang rawat inap di RSUP Dr. Sardjito merupakan kasus rujukan sebesar 134 orang (71,7\%), dengan 15 orang (8\%) perawatan di ICU dan sebagian besar dirawat di IMP sebanyak 174 orang (92\%). Kejadian Intrauterine Fetal Death (IUFD) pada subyek penelitian sebesar 13 orang (7\%).

TABEL 1. Karakteristik Data Penelitian

\begin{tabular}{|c|c|c|}
\hline Variabel & Jumlah & Persen \\
\hline \multicolumn{3}{|l|}{ Usia } \\
\hline$<20$ tahun & 2 & 1,1 \\
\hline 20-35 tahun & 111 & 59,4 \\
\hline$>35$ tahun & 74 & 39,6 \\
\hline \multicolumn{3}{|l|}{ Paritas } \\
\hline Primigravida & 60 & 32,1 \\
\hline Multigravida & 127 & 67,9 \\
\hline \multicolumn{3}{|l|}{ Indeks Massa Tubuh } \\
\hline Normal $(18,5-24,9$ kg/m²) & 29 & 15,5 \\
\hline Overweight $\left(25-29,9 \mathrm{~kg} / \mathrm{m}^{2}\right)$ & 57 & 30,5 \\
\hline Obesitas $\left(\geq 30 \mathrm{~kg} / \mathrm{m}^{2}\right)$ & 97 & 51,9 \\
\hline \multicolumn{3}{|l|}{ Pendidikan } \\
\hline$\leq 9$ tahun $(\mathrm{SD}, \mathrm{SMP})$ & 68 & 36,4 \\
\hline$>9$ tahun $(\mathrm{SMA}, \mathrm{PT})$ & 119 & 63,6 \\
\hline \multicolumn{3}{|l|}{ Penjaminan } \\
\hline Umum & 68 & 36,4 \\
\hline Asuransi & 119 & 63,6 \\
\hline \multicolumn{3}{|l|}{ Rujukan } \\
\hline Ya & 134 & 71,7 \\
\hline Tidak & 53 & 28,3 \\
\hline \multicolumn{3}{|l|}{ Tempat perawatan } \\
\hline ICU & 15 & 8 \\
\hline Non ICU & 174 & 92 \\
\hline \multicolumn{3}{|l|}{ Intrauterine Fetal Death (IUFD) } \\
\hline Ya & 13 & 7 \\
\hline Tidak & 174 & 93 \\
\hline \multicolumn{3}{|l|}{ Skor MEOWS } \\
\hline Skor $\geq 8$ & 70 & 37,4 \\
\hline Skor $<8$ & 117 & 62,6 \\
\hline
\end{tabular}

Penilaian terhadap kemampuan suatu test dilakukan dengan menggunakan luas area under the curve (AUC). Nilai AUC berkisar dari 0-1 dimana kemampuan suatu test dinyatakan baik jika AUC $\geq 0,7$. Pada data penelitian ini nilai AUC adalah 0,635.

TABEL 2. Area Under the Curve

\begin{tabular}{cccc}
\hline Area & Std. Error & $\begin{array}{c}\text { Asymptotic } \\
\text { Sig. }\end{array}$ & $\begin{array}{c}\text { Asymptotic } \\
\text { Cl 95\% }\end{array}$ \\
\hline 0,635 & 0,095 & 0,083 & $0,449-0,821$ \\
\hline
\end{tabular}

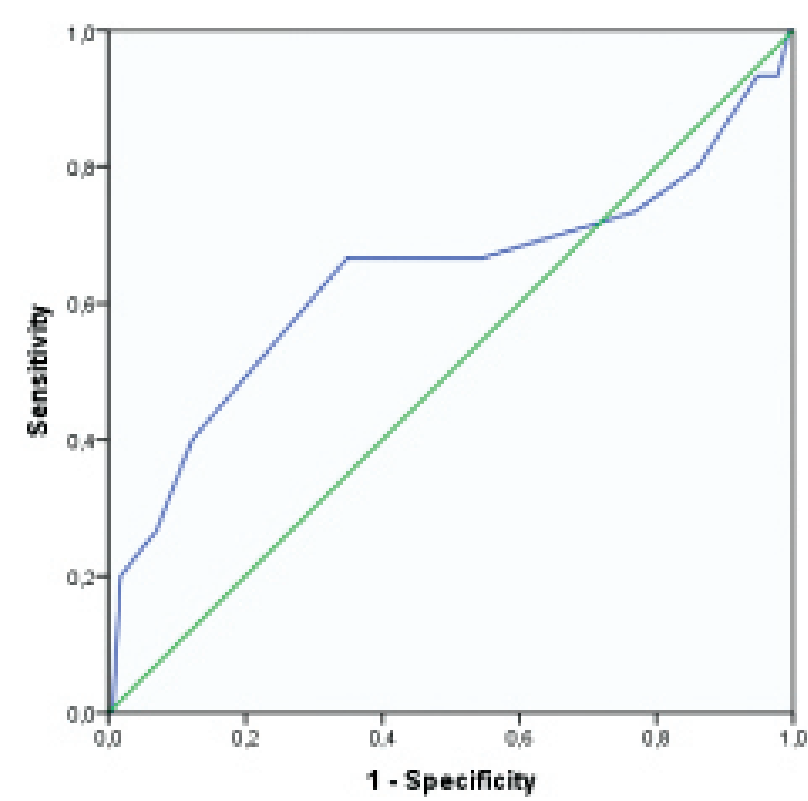

GAMBAR 1. Kurva ROC

Penelitian ini dapat menjadi salah satu screening dalam menentukan level of care dari pasien preeklampsia berat. Sensitifitas dan spesifitas dari data penelitian dihitung untuk mendapatkan cut off point skor MEOWS.

Perhitungan cut off point seperti yang terlihat dari Gambar 3 tampak bahwa titik potong berada pada angka skor 7,5. Nilai LR+ terbaik pada skor 7,5; 8,5 dan 9,5; namun nilai LR-terendah berada pada skor 7,5 dan 8,5. Skor terbaik berada pada nilai 7,5-8,5; dimana skor MEOWS merupakan bilangan bulat, maka nilai cut off point berada pada skor 8 .

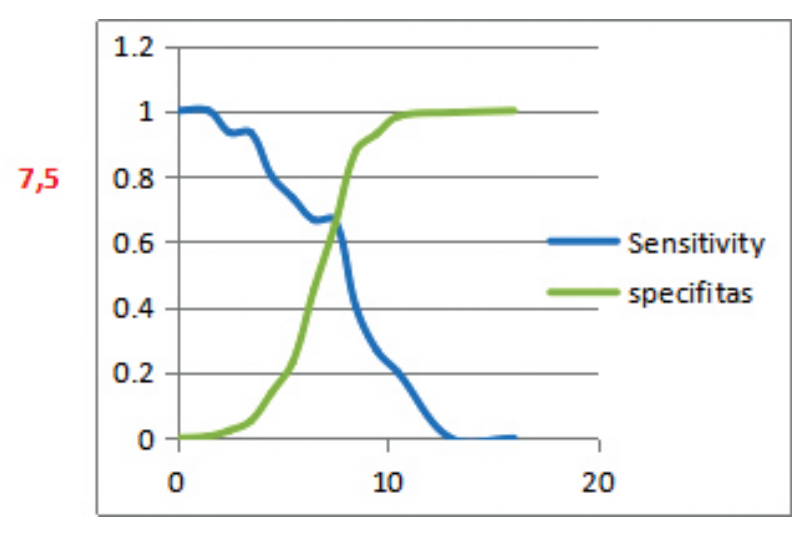

GAMBAR 2. Kurva cut off point skor MEOWS dengan perawatan di ICU

Tabel 3 menggambarkan adanya perbedaan yang bermakna antara skor MEOWS tinggi dan skor MEOWS rendah yang dirawat di ICU dengan nilai $\mathrm{p}$ 
sebesar 0,015 ( $p>0,05)$. Nilai RR menunjukkan bahwa pasien dengan skor MEOWS tinggi mempunyai kemungkinan lebih tinggi 3,34 kali lebih besar untuk dirawat di ICU dibandingkan dengan skor MEOWS rendah.

Tabel 4 menggambarkan adanya perbedaan bermakna kejadian IUFD antara pasien dengan skor MEOWS tinggi dan skor MEOWS rendah. Nilai RR sebesar 9,91 menunjukkan bahwa pasien dengan skor MEOWS tinggi mempunyai kemungkinan lebih tinggi 9,91 kali lebih besar untuk kejadian bayi IUFD dibandingkan dengan skor MEOWS rendah.
Perhitungan analisis multivariat yang berfokus pada perawatan di ICU digambarkan pada Tabel 5. Hasil analisis didapatkan bahwa skor MEOWS tinggi akan meningkatkan risiko pasien akan dirawat di ICU sebesar 4,07 kali lebih tinggi dibandingkan pasien dengan skor MEOWS rendah (RR 4,07; 95\% Cl 1,2812,92).

Pada variabel paritas didapatkan bahwa primigravida akan meningkatkan risiko pasien dirawat di ICU sebesar 2,3 kali lebih tinggi dibandingkan multigravida, namun tidak bermakna secara statistik (RR 2,298; 95\% Cl 0,665-7,944).

Tabel 3. Perbandingan Proporsi skor MEOWS dengan Perawatan di ICU

\begin{tabular}{lrrcccc}
\hline \multirow{2}{*}{ Skor MEOWS } & \multicolumn{2}{c}{ Rawat ICU } & & \multirow{2}{*}{ Persen Ya } & RR (95\% Cl) & Nilai P \\
\cline { 2 - 3 } & Ya & Tidak & & & & \\
\hline$\geq 8$ (tinggi) & 10 & 60 & & 14,3 & $3,34(1,19-9,38)$ & 0,015 \\
$<8$ (rendah) & 5 & 112 & & 4,3 & 1 (referent) & \\
\hline
\end{tabular}

Tabel 4. Perbandingan Skor MEOWS dengan kejadian IUFD

\begin{tabular}{lrrcccc}
\hline \multirow{2}{*}{ Skor MEOWS } & \multicolumn{2}{c}{ Bayi IUFD } & \multirow{2}{*}{ Persen Ya } & RR (95\% Cl) & P Value \\
\cline { 2 - 4 } & \multicolumn{2}{c}{ Ya } & Tidak & & & \\
\hline Skor $\geq 8$ (tinggi) & 11 & 59 & 15,7 & $9,91(2,098-40,27)$ & 0,000 \\
Skor $<8$ (rendah) & 2 & 115 & 1,7 & 1 & \\
\hline
\end{tabular}

Tabel 5. Analisis Regresi Logistik

\begin{tabular}{|c|c|c|c|}
\hline & $\mathbf{p}$ & $\mathbf{R} \mathbf{R}$ & $\mathrm{Cl} 95 \%$ \\
\hline \multicolumn{4}{|l|}{ Skor MEOWS } \\
\hline Skor $\geq 8$ (tinggi) & 0,017 & 4,072 & $1,283-12,925$ \\
\hline Skor <8 (rendah) & 1 & & \\
\hline \multicolumn{4}{|l|}{ Usia } \\
\hline$<20$ dan $>35$ tahun & 0,731 & 1,255 & $0,344-4,585$ \\
\hline 20-35 tahun & 1 & & \\
\hline \multicolumn{4}{|l|}{ Paritas } \\
\hline Primigravida & 0,188 & 2,298 & $0,665-7.944$ \\
\hline Multigravida & 1 & & \\
\hline \multicolumn{4}{|l|}{ Indeks Massa Tubuh } \\
\hline Obesitas $\left(>30 \mathrm{~kg} / \mathrm{m}^{2}\right)$ & 0,087 & 0,350 & $0,105-1,163$ \\
\hline Non Obesitas $\left(\leq 30 \mathrm{~kg} / \mathrm{m}^{2}\right)$ & 1 & & \\
\hline \multicolumn{4}{|l|}{ Pendidikan } \\
\hline Rendah (SD-SMP) & 0,724 & 0,801 & $0,234-2,745$ \\
\hline Tinggi (SMA-PT) & 1 & & \\
\hline \multicolumn{4}{|l|}{ Penjaminan } \\
\hline Umum & 0,726 & 0,808 & $0,245-2,661$ \\
\hline Asuransi & 1 & & \\
\hline \multicolumn{4}{|l|}{ Riwayat Hipertensi } \\
\hline $\mathrm{Ya}$ & 0,629 & 1,373 & $0,380-4,958$ \\
\hline Tidak & 1 & & \\
\hline
\end{tabular}


Berdasarkan penelitian diatas didapatkan karakteristik subyek penelitian dari variabel usia dan indeks massa tubuh (IMT) relatif sebanding. Sementara dari paritas menunjukkan sebagian besar pasien PEB yang dirawat adalah multigravida, hal ini terjadi karena jumlah pasien multigravida merupakan akumulasi dari pasien dengan kehamilan kedua dan seterusnya.

Tingkat pendidikan sebagian besar subyek penelitian adalah SMA dan Perguruan Tinggi. Pada variabel penjaminan tampak bahwa sebagian besar pasien yang datang sudah mempunyai asuransi $(63,6 \%)$. Hal ini dapat terjadi karena semakin tinggi tingkat pendidikan, maka kebutuhan akan pentingnya penjaminan kesehatan akan semakin tinggi.

Sejumlah 71,7\% merupakan kasus rujukan, hal ini terjadi karena RSUP Dr. Sardjito merupakan pusat rujukan tipe $A$ yang menerima rujukan dari wilayah DIY maupun Jawa Tengah.

Perhitungan menggunakan kurva ROC, menghitung sensitifitas dan spesifitas antara skor MEOWS dengan perawatan ICU, didapatkan nilai cut off point-nya adalah 7,5 . Setelah dilakukan perhitungan tampak bahwa skor terbaik berada pada nilai 7,58,5. Skor MEOWS merupakan bilangan bulat, maka nilai cut off point berada pada skor 8. Pasien dengan skor MEOWS 6 dan 7, walaupun merupakan skor risiko tinggi namun dapat dipertimbangkan untuk dirawat di non ICU bila tidak ada kebutuhan akan ventilasi mekanik.

Hasil analisis bivariat dengan uji Chi-Square untuk variabel skor MEOWS dan perawatan di ICU adalah $p=0,015$ dan $\operatorname{RR}(\mathrm{Cl} 95 \%)=3,34(1,19-9,38)$, hal ini menunjukkan bahwa dalam penelitian ini ditemukan hubungan antara skor MEOWS tinggi (skor $\geq 8$ ) dengan perawatan di intensif. Pasien preeklamsia berat dengan skor tinggi memiliki risiko perawatan intensif 3,34 kali lipatnya daripada skor MEOWS rendah. Perawatan intensif tidak serta merta merujuk kepada ICU, namun pasien dengan skor MEOWS yang tinggi memiliki kebutuhan level of care yang lebih tinggi juga baik dari kebutuhan alat (ventilator, syringe pump, dll) maupun kebutuhan sumberdaya manusia (dokter dan perawat yang terlatih kegawatdaruratan.
Hasil analisis bivariat dengan uji Chi-Square untuk variabel skor MEOWS dan kejadian IUFD adalah $p=0,000$ dan RR (Cl 95\%) =9,91 (2,098$40,27)$, hal ini menunjukkan bahwa dalam penelitian ini ada hubungan antara skor MEOWS dengan kejadian IUFD. Risiko bayi IUFD pada pasien preeklamsia berat dengan skor MEOWS tinggi 9,91 kali lipatnya dibandingkan skor MEOWS rendah. Hal ini dapat terjadi karena pasien dengan skor MEOWS tinggi telah mengalami perberatan kondisi klinis baik keadaan umum, tanda vital maupun perburukan organ, sehingga mengganggu sirkulasi uteroplasenta yang berakibat dengan kematian janin.

Analisis dilanjutkan dengan analisis multivariat dengan regresi logistik terhadap keseluruhan variabel, baik variabel bebas, luar, maupun tergantung didapatkan bahwa skor MEOWS tinggi akan meningkatkan risiko pasien akan dirawat di ICU sebesar 4,17 kali lebih tinggi dibandingkan pasien dengan skor MEOWS rendah (RR 4,17; $95 \% \mathrm{Cl} 1,32-13,7)$. Sementara pada variabel paritas didapatkan bahwa primigravida akan meningkatkan risiko pasien akan dirawat di ICU sebesar 2,19 kali lebih tinggi dibandingkan dengan multigravida, namun tidak bermakna secara statistik. Begitupun juga dengan variabel usia dan Indeks Massa Tubuh tidak berbeda bermakna secara statistik. Paritas (primigravida) merupakan salah satu faktor risiko terkait dengan maternal dari kejadian preeklamsia berat, namun bukan merupakan faktor risiko pasien akan dirawat di ICU.

\section{KESIMPULAN DAN SARAN}

Pasien preeklamsia berat dengan skor MEOWS $\geq 8$ memiliki risiko untuk dirawat di ICU 3,34 kali lipat dibandingkan dengan pasien preeklamsia berat dengan skor MEOWS $<8$. Pasien preeklamsia berat dengan skor MEOWS $\geq 8$ memiliki risiko untuk melahirkan bayi mati 9,91 kali lipat dibandingkan dengan pasien preeklamsia berat dengan skor MEOWS < 8 . Nilai cut off point pasien preeklamsia berat yang dirawat di ICU adalah skor 8 .

\section{DAFTAR PUSTAKA}

1. Saifuddin AB. Upaya Safe Motherhood dan Making Pregnancy Safer. Dalam Bunga Rampai Obstetri dan 
Ginekologi Sosial, Yayasan Bina Pustaka Sarwono Prawirohardjo. Jakarta. 2005.

2. Indonesian Demographic and Health Survey 2012. Tersedia di htttp://www.depkes.go.id/

3. Singh S, McGlennan A, England A, Simons R. A validation study of the CEMACH recommended modified early obstetric warning system (MEOWS). Anaesthesia 2012;67:12-8.

4. Pedoman Nasional Pelayanan Kedokteran. Preeklamsia. POGI. 2016.

5. Norwitz E, Hsu CD, Repke J. Acute Complications of Preeclampsia. Clinical Obstetrics and Gynecology 2002;45:308-29.

6. Osungbade KO, Ige OK. Public Health Perspectives of Preeclampsia in Developing Countries: Implication for Health System Strengthening. Journal of Pregnancy. 2011. (Diakses pada 20 Februari 2017). Diunduh dari: http://www.hindawi.com/journals/ jp/2011/481095
7. Mackintosh N, Watson K, Rance S, Sandall J. Value of a modified early obstetric warning system (MEOWS) in managing maternal complications in the peripartum period: an ethnographic study. BMJ Qual Saf 2014;23:26-34.

8. Carle C, Alexander P, Columb M, Johal J. Design and internal validation of an obstetric early warning score: secondary analysis of the Intensive Care National Audit and Research Centre Case Mix Programme Database. Anaesthesia 2013;68:35467. 